\title{
Author Correction: A statistical estimator for determining the limits of contemporary and historic phenology
}

William D. Pearse D, Charles C. Davis, David W. Inouye BD, Richard B. Primack and T. Jonathan Davies

Correction to: Nature Ecology \& Evolution https://doi.org/10.1038/s41559-017-0350-0, published online 06 November 2017.

In the version of this Article originally published, the rate of change plotted in Figure 2 was incorrect because of a coding error. The corrected figure is shown below. In the original Figure 2 legend, the onset of flowering slope was given as '0.99, 95\% CI: 0.90-1.08', the cessation of flowering slope was given as ' $1.02,95 \%$ CI: $0.91-1.13$ ', and the $r_{\text {adjusted }}^{2}$ for each model was given as greater than $74 \%$. The correct values are '1.04, 95\% CI: $0.97-1.12$ ', '1.25, 95\% CI: $0.87-1.62$ ', and ' $60 \%$ ', respectively. The main text and the conclusion that the slopes of these relationships are statistically indistinguishable from 1.00 are unchanged. These errors have now been corrected in the PDF and HTML versions of the article. The authors are grateful to A. Iler, who drew attention to this issue.
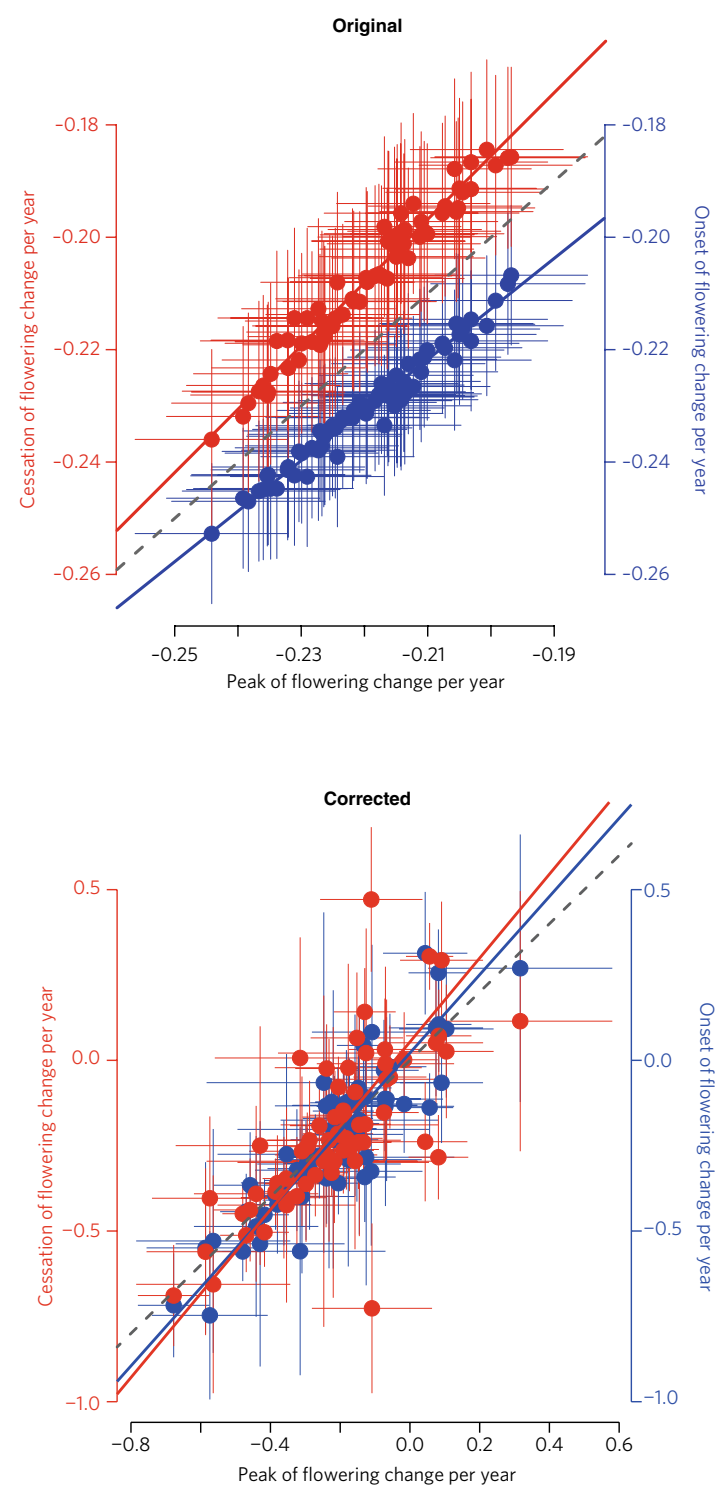

Fig. 2 | Orginal and Corrected. 